\title{
What or Where? The Meaning of Referential Human Pointing for Dogs (Canis familiaris)
}

AQ: au

\author{
Tibor Tauzin \\ Central European University and Budapest University of \\ Technology and Economics
}

Anna Kis

Eötvös Loránd University and Hungarian Academy of Sciences, Budapest, Hungary

\author{
Andor Csík \\ Budapest University of Technology and Economics
}

József Topál

Hungarian Academy of Sciences, Budapest, Hungary

\begin{abstract}
Dogs have a unique capacity to follow human pointing, and thus it is often assumed that they can comprehend the referential meaning of such signals. However, it is still unclear whether dogs perceive human directional gestures as signals referring to a target object (indicating what to manipulate) or a spatial cue (indicating where to do something). In the present study, we investigated which of these alternative interpretations may explain dogs' responses to human pointing gestures in ostensive communicative and nonostensive cuing contexts. To test whether dogs select the cued object or the cued location, subjects were presented with 2 alternative object-choice trials. An experimenter first attracted the attention of the dog either by calling the dog's name and looking at it (ostensive condition, $n=24$ ) or by clapping the hands (nonostensive condition, $n=24$ ) then pointed at 1 of 2 different toy objects. Subsequently, the experimenter switched the location of the 2 target objects in full view of the dogs by grasping the objects and making a $180^{\circ}$ turn. Dogs were then allowed to choose between the 2 objects. In the ostensive condition, dogs showed a significant bias toward the cued location compared with the nonostensive condition in which they performed at chance. These results suggest that pointing refers to a direction or location for dogs, but only if they are addressed with ostensive cues that indicate the communicative intention of the signaler.
\end{abstract}

Keywords: dog, pointing, location bias, object bias, ostensive communication

Use of referential communication has long been thought to be unique to humans (e.g., Darwin, 1872). However, decades of extensive research has revealed that some other species, including mammals (e.g., bottlenose dolphins: King \& Janik, 2013; chimpanzees: Slocombe \& Zuberbühler, 2005) and birds (e.g., ravens: Bugnyar, Kijne, \& Kotrschal, 2001) can also produce and respond adequately to a limited set of referential vocal signals that indicate

Tibor Tauzin, Cognitive Development Center, Central European University, and Department of Cognitive Science, Budapest University of Technology and Economics; Andor Csík, Department of Cognitive Science, Budapest University of Technology and Economics; Anna Kis, Department of Ethology, Eötvös Loránd University, and Institute of Cognitive Neuroscience and Psychology, Research Centre for Natural Sciences, Hungarian Academy of Sciences, Budapest, Hungary; József Topál, Institute of Cognitive Neuroscience and Psychology, Research Centre for Natural Sciences, Hungarian Academy of Sciences.

Supported by the Hungarian Scientific Research Fund (Grant OTKA K112138). We thank Julie Hecht for correcting English in the manuscript and Fruzsina Elekes and Ágnes Melinda Kovács for their valuable help.

Correspondence concerning this article should be addressed to Tibor Tauzin, Cognitive Development Center, Central European University, Október 6. u. 7, 1051 Budapest, Hungary. E-mail: tauzint@ceu.hu specific objects or events in the environment (Liebal, Waller, Slocombe, \& Burrows, 2013). It remains, however, an open question whether these signals are information-based in the sense that they reduce uncertainty in the receiver (Carazo \& Font, 2010). In fact, production of these signals is context-specific (a specific contextual cue triggers them), and the response to them is stimulus-independent (might occur in the absence of the referent as well), thus, these signals have been described as "functionally referential" to differentiate them from the referential signals produced by humans (Wheeler \& Fischer, 2012). Importantly, some nonhuman species can also understand referential cues that are not context-specific, namely, directional gestures such as pointing or gazing. For instance, elephants (Smet \& Byrne, 2013), seals (Scheumann \& Call, 2004), and dolphins (Herman et al., 1999) can rely on human pointing in an object choice task, even though pointing is not part of their own signal repertoire, while ravens (Pika \& Bugnyar, 2011) and fish (Plectropomus pessuliferus marisrubi and Plectropomus leopardus: Vail, Manica, \& Bshary, 2013) can produce specific referential gestures and can also adequately respond to them.

Responsiveness to human directional gestures has also been investigated in domesticated species, for example, in cats (Miklósi, Pongrácz, Lakatos, Topál, \& Csányi, 2005), horses (Proops, Walton, \& McComb, 2010), and ferrets (Hernádi, Kis, Turcsán, \& Topál, 2012). These skills have been most extensively studied in dogs (e.g., Wobber 
TAUZIN, CSÍK, KIS, AND TOPÁL

\& Kaminski, 2011), whose social and communicative abilities show some overlap with those of humans (Bräuer, Kaminski, Riedel, Call, \& Tomasello, 2006). Previous findings have suggested that dogs can rely on various types of human directional gestures, such as different types of pointing gestures in an object choice task where at least one limb of the signaler protruded from the body contour (Soproni, Miklósi, Topál, \& Csányi, 2002). Dogs' performance in these tasks is comparable to that of 2-year-old children (Lakatos, Soproni, Dóka, \& Miklósi, 2009), and, importantly, it seems that, like infants (see Csibra, 2010), dogs rely on ostensive cues such as eye contact or high-pitched speech to recognize when a referential gesture is being addressed to them (Kaminski, Schulz, \& Tomasello, 2012). Both human infants (Behne, Carpenter, \& Tomasello, 2005) and dogs (Kaminski et al., 2012; Tauzin, Csík, Kis, Kovács, \& Topál, 2015) are better at following human pointing if the directional gesture is preceded by ostensive signals that indicate a person's communicative intention.

This striking analogy in observable behavior, however, does not imply that the "meaning" of pointing is the same for both species. Referential pointing might have a different range of functions in human infants than in dogs, because pointing can be performed and interpreted as a declarative, interrogative, or imperative gesture. Declarative pointing is produced by infants to indicate an event or object of interest in the environment (Liszkowski, Carpenter, Henning, Striano, \& Tomasello, 2004) in order to share attention and experience with someone else (Tomasello \& Carpenter, 2007), while interrogative pointing is an epistemic request toward a knowledgeable person about the referent (Kovács, Tauzin, Téglás, Gergely, \& Csibra, 2014). In contrast, an imperative pointing gesture would mean that the signaler requests an action on a specific referent at a particular location (Bates, Camaioni, \& Volterra, 1975). Dogs' response to human pointing could reflect an imperative interpretation of pointing (Kaminski et al., 2012; Szetei, Miklósi, Topál, \& Csányi, 2003), however, it is also possible that dogs interpret pointing as simply providing useful information about the referent (Scheider, Kaminski, Call, \& Tomasello, 2013).

What seems common in these different explanations is that, regardless of its function, the understanding of pointing implies integration of signal and context to infer what was pointed at (Wheeler \& Fischer, 2012), because pointing does not have a fixed referent (Liebal et al., 2013). It has been found that even 9-monthold human infants interpret ostensive pointing as referring to a target object and not as a signal indicating a specific location (Yoon, Johnson, \& Csibra, 2008). It seems that for humans communicative pointing carries information about the target object (by focusing the observer's attention on the object's properties) and

AQ: 2 not about the location of the designated object. Although dogs and human infants readily grasp the informing feature of human pointing, it is still unclear whether dogs, like infants, perceive pointing as a signal referring to a target object or as referring to a location indicating where to go.

To investigate this question, we designed an object choice paradigm where after a human pointed at one of two clearly different target objects, the location of the objects were switched in full view of the dog. We hypothesized that if, for dogs, the identity of the referent object is more relevant than its location, dogs would select the cued object at the new location. However, if dogs perceive pointing as a signal referring to a certain location, they would select the nonindicated object at the cued location. We also tested whether the communicative context of pointing affected dogs' responses. Therefore, dogs were presented with human pointing gestures either in an ostensive (calling the dog's name and making eye contact with the dog) or in a nonostensive (clapping of hands without eye contact) condition.

\section{Method}

\section{Participants}

Fifty-nine toy-motivated pet dogs (ostensive condition: $n=30$; 15 males; $M_{\text {age }}=3.63$ years, $S D=2.43 ; 11$ mix breeds and 19 purebreds from 13 different breeds; nonostensive condition: $n=$ 29; 14 males; $M_{\text {age }}=4.38$ years, $S D=2.53$; eight mix breeds and 21 purebreds from 14 different breeds) were recruited from the Family Dog Project database of the Department of Ethology, Eötvös Loránd University. We excluded $11 \mathrm{dogs}$ (six from the ostensive and five from the nonostensive condition). Four dogs were excluded due to a constant side bias (i.e., selecting the same side in each trial) because the behavior of these dogs was assumed to be independent of the pointing of the experimenter, thus dogs' choice behavior could not be informative regarding our experimental question (how dogs interpret pointing). Another seven dogs were excluded because at least half of their test trials were invalid due to either the influence of the owner, experimenter error, or failure to search. All exclusions were based on a priori criteria after the offline coding of dog behavior but before completion of data collection, except for in the case of one dog showing in-test anxiety where testing concluded after 6 trials. There were 48 dogs AQ: 5 in the final sample, $24 \mathrm{dogs}$ in the ostensive condition (12 males; $M_{\text {age }}=3.7$ years, $S D=2.56 ; 10$ mix breeds and 14 purebreds from 11 different breeds) and 24 dogs in the nonostensive condition $\left(11\right.$ males; $M_{\text {age }}=4.87, S D=2.44 ; 6$ mix breeds and 18 purebreds from 13 different breeds).

\section{Procedure}

Before starting the experiment, the owner led the dog to the experimental room $(3.0 \times 5.0 \mathrm{~m})$ and let it explore freely for 3 min. The owner then sat down at a predetermined point holding the dog by its collar facing Experimenter 1 (E1) who stood at the midline of the testing room, approximately $2 \mathrm{~m}$ from the dog. Experimenter 2 (E2) stood next to the dog.

\section{Ostensive Condition}

The experiment consisted of eight trials organized into four separate blocks. In the first block, E1 put two distinct, 18-cm tall plush toys on the ground in reaching distance (approximately $75 \mathrm{~cm}$ ) to the left and right of E1. The plush toys were presented in pairs, either a brown kangaroo with a white-yellow pig or a yellow-red bear with a beige rabbit, none of which the dog had seen before the experiment. The dog was prevented from witnessing the placement of the toys by E2 who placed a dark blue plastic occluder $(1 \times 0.75 \mathrm{~m})$ between the dog and E1. After the plush toys were placed, E1 took the initial position in which he stood equidistant between the two target objects, bent his arms in front of his torso, contacted his elbows and wrists with closed fists, lowering his head and looking at the ground (see Figure 1). After E2 removed the occluder, E1 looked at the dog and F1 


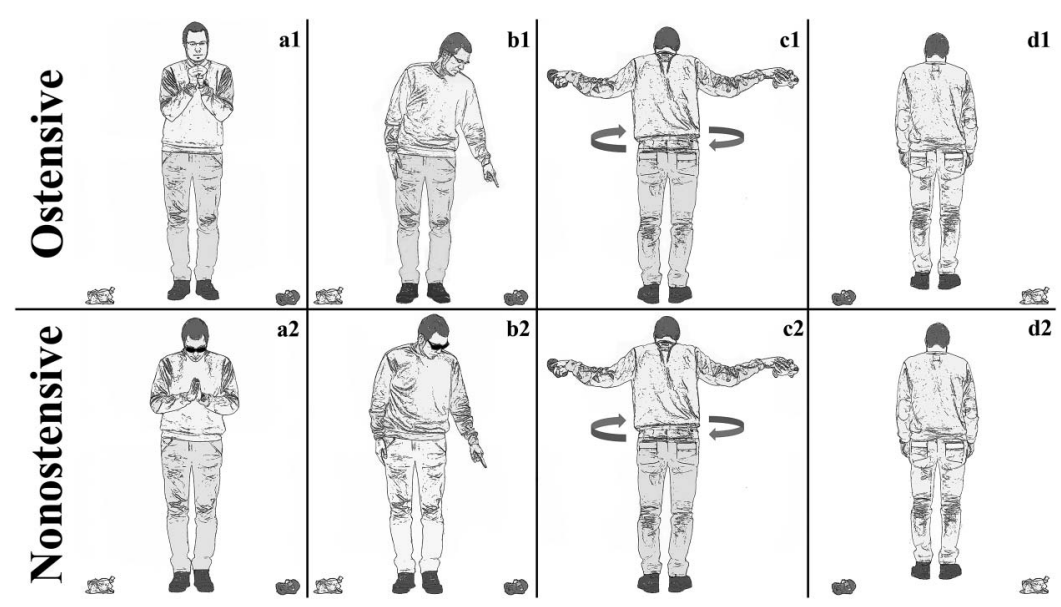

Figure 1. Steps of the ostensive $(\mathrm{a} 1-\mathrm{d} 1)$ and nonostensive $(\mathrm{a} 2-\mathrm{d} 2)$ cueing procedure. Step 1: ostensive addressing (looking at the dog and calling the dog's name) (a1) and getting the dog's attention by nonostensive clapping (a2). Step 2: momentary pointing and looking at the target (b1-b2). Step 3: $180^{\circ}$ turn to switch the location of the plush toys $(\mathrm{c} 1-\mathrm{c} 2)$. Step 4: final arrangement of the objects and taking a step forward $(\mathrm{d} 1-\mathrm{d} 2)$.

called its name ("Look, [dog's name]!"). When the dog looked at his face, E1 pointed at the target object ( $1 \mathrm{~s}$ momentary pointing) while also turning his head and looking at the toy. After the point, E1 assumed his initial position and then crouched down, grasped the two plush toys, and slowly turned $180^{\circ}$ with arms extended to switch the side of the two toys. E1 stopped turning when his back was to the dog, and then he simultaneously placed the toys on the ground, stood up, lowered his arms, and stepped forward (away from the dog). Thus, E1 was facing away from the dog during the choice phase so not to influence the dog's behavior. At that moment, the owner was allowed to release the dog, prompting it verbally (e.g. "You may go!" or

AQ: 7 "Fetch it!"), but without using any gestures to direct the dog. After the dog selected a toy (see Data Analysis section), E1 picked up the nonchosen object. Then, or if the dog did not approach one of the plush toys within $20 \mathrm{~s}$, the owner called the dog back. The second trial followed the same procedure, except that the target object's initial position, and therefore the direction of pointing, was opposite that AQ: 8 used in the first trial.

In the second block, the owner was instructed to lead the dog to the opposite side of the room, sit down, and face the dog toward the initial location. This was done to avoid an allocentric side bias. E1 then used the second pair of plush toys to prevent the emergence of a constant preference for one of the plush toys. The order of left/right pointing in the second block was the same as in the first. The third and the fourth blocks were exactly the same as the first and the second blocks, respectively. The direction of the first point and the plush toy that was pointed at first were counterbalanced between subjects.

\section{Nonostensive Condition}

The procedure in the nonostensive condition was exactly the same as that of the ostensive condition, except that E1 wore black sunglasses and avoided looking at or talking to the dog. Thus, E1 looked at the ground with lowered head when he called the dog's attention and he used nonverbal signals (clapping the hands) instead of calling the subject by name.

\section{Data Collection and Analysis}

Test events were recorded and videos were analyzed offline. A choice was coded if the dog approached a toy object within $0.5 \mathrm{~m}$ with his nose. A second coder scored $50 \%$ of the dogs in both conditions ( $n=24$ subjects in total). Interrater reliability was almost perfect (Cohen's $\kappa=0.98$ ).

To examine dogs' performance, we calculated the average normalized difference score based on the number of approaches to the cued location versus the cued object for each dog (thus, 0 represents chance level on a scale from -1 to +1 , positive values indicating a bias toward the cued side and negative values a bias toward the cued object). We employed Wilcoxon signed-ranks test to investigate whether there was a significant difference between the difference scores and chance level in both conditions. Difference scores were also compared using a Mann-Whitney test between the two conditions to see whether ostension had an effect on dogs' choice behavior.

\section{Results}

Dogs in the ostensive condition selected the cued side more often than the cued object $\left(M_{\text {difference score }}=0.23\right), 95 \%$ confidence interval (CI) $[0.09,0.38]$. Their bias toward the cued location was significant compared with chance level $(z=2.614, p=.007, r=.533)$. However, in the nonostensive condition, dogs did not have a bias toward the cued location or the cued object $\left(M_{\text {difference score }}=-0.03\right)$, $95 \%$ CI $[-0.15,0.1]$. Their performance did not differ significantly from chance level $(z=0.253, p=.834, r=.051)$. The difference between the two conditions was significant $(z=2.432, p=.014, r=$ .351 ), showing that in the ostensive condition dogs preferred to choose the cued location significantly more often than in the nonostensive condition (see Figure 2).

\section{Discussion}

The present study investigated two possible "meanings" of human pointing gestures for dogs. Specifically, we tested whether pointing 


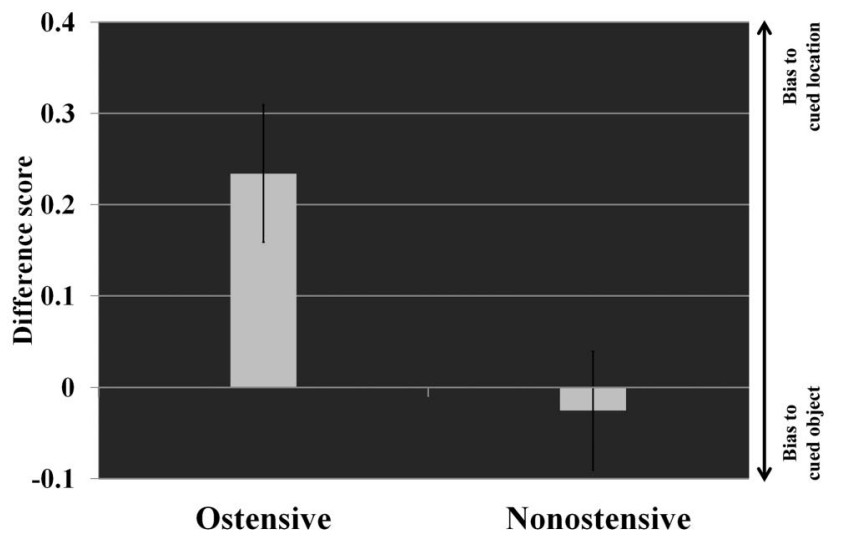

Figure 2. Dogs' choice behavior in the ostensive and nonostensive conditions. Bar graphs show the average normalized difference scores. Error bars show SEM.

was an object-related signal, which referred to a target object, or whether it was a direction-related gesture, which indicated a relevant location or direction. Our results suggest that dogs' performance is consistent with the directional interpretation of pointing, because-at least in the ostensive condition-they selected the cued location reliably above chance and tended to ignore the cued object. The above interpretation of pointing is in line with what has been found in apes (Haun, Call, Janzen, \& Levinson, 2006), which exhibit a preference for place over feature in a spatial memory task. Note, however, that apes can also use feature-based strategy in food search tasks (Kanngiesser \& Call, 2010).

The finding that dogs in the nonostensive condition chose randomly reflects that, in the absence of cues to express communicative intent, dogs probably did not treat the experimenter's pointing as relevant to them, as has been found in previous research (e.g., Kaminski et al., 2012). The direct comparison of the ostensive and nonostensive conditions provided further support for this explanation. In fact, we found a significant difference between these conditions, suggesting that ostension modulates dogs' reactions to human pointing gestures, as has been observed in several other contexts (see Topál, Kis, \& Oláh, 2014, for a review). Together, these results imply that, for dogs, pointing in an ostensive context assigns a direction or an area.

The effect of ostensive cues, however, could have different interpretations. It is possible that dogs have an early sensitivity to, and innate predisposition for, human ostensive cues. However, it is also possible that dogs associate their own name and maybe other ostensive communicative cues with significant (mainly positive) consequences during ontogeny (see, e.g., Elgier, Jakovcevic, Barrera, Mustaca, \& Bentosela, 2009, for a review of the learning effect in dog-human communication). This would imply that ostensive signals are more salient to dogs than nonostensive attention getters and that this difference is learned. In other words, interpretation of human ostensive communicative signals could be grounded within the context of the previously experienced consequences of these signals. In this respect, dogs' understanding could differ from that of human infants because infants can understand unfamiliar ostensive cues (e.g., shivering) as well, and even these cues can trigger gaze-following (Szufnarowska, Rohlfing, Fawcett, \& Gredebäck, 2014).
Moreover, one might argue that the clapping of hands in the nonostensive condition distracted or even frightened dogs in the present study. However, a recent study has suggested that dogs AQ: 9 perceive the clapping of hands that precedes pointing as an attention getter, and it can even enhance their performance in an object choice task (Tauzin et al., 2015). However, this result does not rule out the possibility that there might be a difference between the attention-getting properties of verbal addressing and clapping.

One could also argue that, in the present experiment, dogs were misled by the $180^{\circ}$ turn where the location of the objects was switched because, in some previous studies, dogs have had difficulties understanding a similar rotation. For instance, Miller, Gipson, Vaughan, Rayburn-Reeves, and Zentall (2009) reported that dogs were unable to find a hidden object in a container at either end of a beam when the container was moved from the left side to the right (or vice versa) by rotating the beam $180^{\circ}$. In the present study, however, there was no need for dogs to recall previous scenes because there was no hiding and the visual features of the target objects were clearly different (unlike the containers). Moreover, dogs could monitor the actual location of the objects during the trials.

Thus, there are reasons to assume that dogs were not simply misled by the $180^{\circ}$ turning, rather that they were driven by the pointing cue. However, in contrast to human infants, who, in an ostensive context, preferentially encode the features of objects at the expense of encoding their locations (Yoon et al., 2008), dogs followed the direction of the ostensive pointing disregarding to which object the experimenter pointed. This suggests that, al- AQ: 11 though there are some similarities between the two species at the behavioral level, the mechanism behind understanding human pointing might differ between humans and dogs (see, e.g., Topál, Gergely, Erdőhegyi, Csibra, \& Miklósi, 2009, for a similar conclusion in the A-not-B paradigm). Although this location bias could also be interpreted as misunderstanding the pointing gesture, it should be noted that pointing can have more than one valid meaning (see, e.g., Kovács et al., 2014). For dogs, the pointing gesture might indicate a relevant location or direction, whereas for humans pointing can convey information about an object's properties (Kaminski, 2009). From this perspective, our results suggest a crucial difference in the default "meaning" of ostensive pointing for dogs and humans. This discrepancy, however, most probably reflects differences in the cognitive mechanisms of the two species, despite a possible functional analogy in behavior.

\section{References}

Bates, E., Camaioni, L., \& Volterra, V. (1975). The acquisition of performatives prior to speech. Merrill-Palmer Quarterly, 21, 205-226.

Behne, T., Carpenter, M., \& Tomasello, M. (2005). One-year-olds comprehend the communicative intentions behind gestures in a hiding game. Developmental Science, 8, 492-499. http://dx.doi.org/10.1111/j.14677687.2005.00440.x

Bräuer, J., Kaminski, J., Riedel, J., Call, J., \& Tomasello, M. (2006). Making inferences about the location of hidden food: Social dog, causal ape. Journal of Comparative Psychology, 120, 38-47. http://dx.doi.org/ 10.1037/0735-7036.120.1.38

Bugnyar, T., Kijne, M., \& Kotrschal, K. (2001). Food calling in ravens: Are yells referential signals? Animal Behaviour, 61, 949-958. http://dx doi.org/10.1006/anbe.2000.1668

Carazo, P., \& Font, E. (2010). Putting information back into biological communication. Journal of Evolutionary Biology, 23, 661-669. http:// dx.doi.org/10.1111/j.1420-9101.2010.01944.x 
Csibra, G. (2010). Recognizing communicative intentions in infancy. Mind \& Language, 25, 141-168. http://dx.doi.org/10.1111/j.1468-0017.2009 .01384. $\mathrm{x}$

Darwin, C. (1872). The expression of emotion in man and animals. London, England: Murray. http://dx.doi.org/10.1037/10001-000

Elgier, A. M., Jakovcevic, A., Barrera, G., Mustaca, A. E., \& Bentosela, M. (2009). Communication between domestic dogs (Canis familiaris) and humans: Dogs are good learners. Behavioural Processes, 81, 402-408. http://dx.doi.org/10.1016/j.beproc.2009.03.017

Haun, D. B. M., Call, J., Janzen, G., \& Levinson, S. C. (2006). Evolutionary psychology of spatial representations in the hominidae. Current Biology, 16, 1736-1740. http://dx.doi.org/10.1016/j.cub.2006.07.049

Herman, L. M., Abichandani, S. L., Elhajj, A. N., Herman, E. Y., Sanchez, J. L., \& Pack, A. A. (1999). Dolphins (Tursiops truncatus) comprehend the referential character of the human pointing gesture. Journal of Comparative Psychology, 113, 347-364. http://dx.doi.org/10.1037/ 0735-7036.113.4.347

Hernádi, A., Kis, A., Turcsán, B., \& Topál, J. (2012). Man's underground best friend: Domestic ferrets, unlike the wild forms, show evidence of dog-like social-cognitive skills. PLoS ONE, 7(8), e43267. http://dx.doi .org/10.1371/journal.pone.0043267

Kaminski, J. (2009). Dogs (Canis familiaris) are adapted to receive human communication. In A. Berthoz \& Y. Christensen (Eds.), Neurobiology of "Umwelt": How living beings perceive the world (pp. 103-107). Berlin, Germany: Springer-Verlag. http://dx.doi.org/10.1007/978-3-540-858973_9

Kaminski, J., Schulz, L., \& Tomasello, M. (2012). How dogs know when communication is intended for them. Developmental Science, 15, 222232. http://dx.doi.org/10.1111/j.1467-7687.2011.01120.x

Kanngiesser, P., \& Call, J. (2010). Bonobos, chimpanzees, gorillas, and orangutans use feature and spatial cues in two spatial memory tasks. Animal Cognition, 13, 419-430. http://dx.doi.org/10.1007/s10071-0090291-3

King, S. L., \& Janik, V. M. (2013). Bottlenose dolphins can use learned vocal labels to address each other. PNAS: Proceedings of the National Academy of Sciences of the United States of America, 110, 1321613221. http://dx.doi.org/10.1073/pnas.1304459110

Kovács, Á. M., Tauzin, T., Téglás, E., Gergely, G., \& Csibra, G. (2014). Pointing as epistemic request: 12-month-olds point to receive new information. Infancy, 19, 543-557. http://dx.doi.org/10.1111/infa.12060

Lakatos, G., Soproni, K., Dóka, A., \& Miklósi, A. (2009). A comparative approach to dogs' (Canis familiaris) and human infants' comprehension of various forms of pointing gestures. Animal Cognition, 12, 621-631. http://dx.doi.org/10.1007/s10071-009-0221-4

Liebal, K., Waller, B., Slocombe, K., \& Burrows, A. (2013). Primate communication: A multimodal approach. New York, NY: Cambridge University Press. http://dx.doi.org/10.1017/CBO9781139018111

Liszkowski, U., Carpenter, M., Henning, A., Striano, T., \& Tomasello, M. (2004). Twelve-month-olds point to share attention and interest. Developmental Science, 7, 297-307. http://dx.doi.org/10.1111/j.1467-7687 .2004.00349.x

Miklósi, A., Pongrácz, P., Lakatos, G., Topál, J., \& Csányi, V. (2005). A comparative study of the use of visual communicative signals in interactions between dogs (Canis familiaris) and humans and cats (Felis catus) and humans. Journal of Comparative Psychology, 119, 179-186. http://dx.doi.org/10.1037/0735-7036.119.2.179

Miller, H. C., Gipson, C. D., Vaughan, A., Rayburn-Reeves, R., \& Zentall, T. R. (2009). Object permanence in dogs: Invisible displacement in a rotation task. Psychonomic Bulletin \& Review, 16, 150-155. http://dx .doi.org/10.3758/PBR.16.1.150

Pika, S., \& Bugnyar, T. (2011). The use of referential gestures in ravens (Corvus corax) in the wild. Nature Communications, 2, 560. http://dx .doi.org/10.1038/ncomms1567
Proops, L., Walton, M., \& McComb, K. (2010). The use of human-given cues by domestic horses, Equus caballus, during an object choice task. Animal Behaviour, 79, 1205-1209. http://dx.doi.org/10.1016/j.anbehav .2010.02.015

Scheider, L., Kaminski, J., Call, J., \& Tomasello, M. (2013). Do domestic dogs interpret pointing as a command? Animal Cognition, 16, 361-372. http://dx.doi.org/10.1007/s10071-012-0577-8

Scheumann, M., \& Call, J. (2004). The use of experimenter-given cues by South African fur seals (Arctocephalus pusillus). Animal Cognition, 7 , 224-230. http://dx.doi.org/10.1007/s10071-004-0216-0

Slocombe, K. E., \& Zuberbühler, K. (2005). Functionally referential communication in a chimpanzee. Current Biology, 15, 1779-1784. http://dx .doi.org/10.1016/j.cub.2005.08.068

Smet, A. F., \& Byrne, R. W. (2013). African elephants can use human pointing cues to find hidden food. Current Biology, 23, 2033-2037. http://dx.doi.org/10.1016/j.cub.2013.08.037

Soproni, K., Miklósi, A., Topál, J., \& Csányi, V. (2002). Dogs' (Canis familiaris) responsiveness to human pointing gestures. Journal of Comparative Psychology, 116, 27-34. http://dx.doi.org/10.1037/0735-7036 .116 .1 .27

Szetei, V., Miklósi, Á., Topál, J., \& Csányi, V. (2003). When dogs seem to lose their nose: An investigation on the use of visual and olfactory cues in communicative context between dog and owner. Applied Animal Behaviour Science, 83, 141-152. http://dx.doi.org/10.1016/S01681591(03)00114-X

Szufnarowska, J., Rohlfing, K. J., Fawcett, C., \& Gredebäck, G. (2014). Is ostension any more than attention? Scientific Reports, 4, 5304. http://dx .doi.org/10.1038/srep05304

Tauzin, T., Csík, A., Kis, A., Kovács, K., \& Topál, J. (2015). The order of ostensive and referential signals affects dogs' responsiveness when interacting with a human. Animal Cognition. Advance online publication. http://dx.doi.org/10.1007/s10071-015-0857-1

Tomasello, M., \& Carpenter, M. (2007). Shared intentionality. Developmental Science, 10, 121-125. http://dx.doi.org/10.1111/j.1467-7687 .2007.00573.x

Topál, J., Gergely, G., Erdőhegyi, A., Csibra, G., \& Miklósi, A. (2009). Differential sensitivity to human communication in dogs, wolves, and human infants. Science, 325, 1269-1272. http://dx.doi.org/10.1126/ science. 1176960

Topál, J., Kis, A., \& Oláh, K. (2014). Dogs' sensitivity to human ostensive cues: A unique adaptation?. In J. Kaminski \& S. Marshall-Pescini (Eds.), The social dog: Behavior and cognition (pp. 319-346). San Diego, CA: Elsevier. http://dx.doi.org/10.1016/B978-0-12-407818-5.00011-5

Vail, A. L., Manica, A., \& Bshary, R. (2013). Referential gestures in fish collaborative hunting. Nature Communications, 4, 1765. http://dx.doi .org/10.1038/ncomms 2781

Wheeler, B. C., \& Fischer, J. (2012). Functionally referential signals: A promising paradigm whose time has passed. Evolutionary Anthropology, 21, 195-205. http://dx.doi.org/10.1002/evan.21319

Wobber, V., \& Kaminski, J. (2011). What do dogs understand about human communicative signals? A novel synthesis. In V. M. Degiovine (Ed.), Dogs: Biology, behavior, and health disorders (pp. 93-109). Hauppauge, NY: Nova Science.

Yoon, J. M. D., Johnson, M. H., \& Csibra, G. (2008). Communicationinduced memory biases in preverbal infants. PNAS: Proceedings of the National Academy of Sciences of the United States of America, 105, 13690-13695. http://dx.doi.org/10.1073/pnas.0804388105

Received December 17, 2014

Revision received May 18, 2015 Accepted May 19, 2015 